\title{
Os padrões de transitividade de processos materiais e a construção de sentidos
}

\section{Transitivity patterns of material processes and the construction of meaning}

\section{Gesieny Laurett Neves Damasceno}

Universidade Federal do Rio de Janeiro, Rio de Janeiro, Rio de Janeiro / Brasil ${ }^{1 *}$ gesieny@yahoo.com.br

\section{Violeta Virginia Rodrigues}

Universidade Federal do Rio de Janeiro, Rio de Janeiro, Rio de Janeiro / Brasil violetarodrigues@uol.com.br

Resumo: Na perspectiva sistêmico-funcional, os papéis principais do sistema de transitividade fornecem o quadro de referência para que a experiência da realidade seja interpretada. Pautado nessa concepção, o presente trabalho objetiva identificar o modo como os componentes do sistema de transitividade são articulados em textos pertencentes ao gênero notícia jornalística e a relação que as codificações encontradas estabelecem com os propósitos sociocomunicativos desse gênero discursivo. Como aporte descritivo-metodológico, elegeram-se oito parâmetros, que visaram a abarcar tanto as propriedades léxico-gramaticais da transitividade como as propriedades pragmáticas e discursivas que atuam nas escolhas efetuadas. São exemplos desses parâmetros: caracterização

\footnotetext{
1* As reflexões expostas neste texto integram a tese de doutorado "A transitividade de processos materiais em notícias jornalísticas", desenvolvida no Programa de PósGraduação em Letras Vernáculas da Universidade Federal do Rio de Janeiro (UFRJ), com o apoio financeiro da CAPES.
} 
dos fazeres transitivos e intransitivos, número de participantes na oração, formas de expressão do significado, objetivos pragmático-discursivos das configurações oracionais e expansão dos processos materiais. O corpus deste estudo compõe-se de 31 notícias jornalísticas, e o recorte de análise compreende 131 orações construídas em torno de processos do tipo material. Para o reconhecimento dos padrões de transitividade presentes nas notícias jornalísticas, utilizamos como ferramenta os Mapas AutoOrganizáveis (do inglês, self-organizing maps - SOM), que se constituem em um tipo de Rede Neural não supervisionada. Tendo em vista a relação de similaridade entre os sinais de entrada, a análise pôde identificar quinze importantes padrões linguísticos, que sintetizam, com bastante eficácia, as escolhas efetuadas no âmbito do sistema de transitividade, bem como os significados construídos nas notícias jornalísticas a partir desses arranjos estabelecidos.

Palavras-chave: Linguística Sistêmico-Funcional (LSF); padrões de transitividade; Mapas Auto-Organizáveis.

Abstract: The main roles of the transitivity system, according to the systemic functional perspective, provide the reference framework so that the experience of reality can be interpreted. Accordingly, the aim of the present study is to identify the way the components of the transitivity system are approached in journalistic texts, as well as the relationship between the herein found codes and the socio-communicative purposes of such discourse genre. We have selected eight descriptive-methodological parameters aiming at covering both the lexico-grammatical properties of transitivity as well as the pragmatic and discursive properties that act in the choices made. Some examples of these parameters are: the featuring of the transitive and intransitive doings, the number of participants in the clause, the ways of expressing the meaning, pragmatic-discursive aims of the clausal configurations and the expansion of the material processes. The corpus in the current study was composed of 31 journalistic news; the analyzed discursive clippings comprised 131 clauses about the material-type processes. The self-organizing maps were used as instruments to find the transitivity patterns in the journalistic news. These maps are a type of non-supervised Neural network. It was possible identifying fifteen important linguistic patterns that effectively synthesize the choices made in the transitivity-system scope, as well as the meanings built in journalistic news from the set of arrangements due to the similarity relation between input signs.

Keywords: Systemic Functional Linguistics (SFL); transitivity patterns; self-organizing maps. 
Recebido em 28 de junho de 2016. Aprovado em 04 de novembro de 2016.

\section{Introdução}

Embasadas nos postulados do funcionalismo sistêmico-funcional, as análises aqui apresentadas se dirigem para a multifuncionalidade das estruturas linguísticas e se distanciam da preocupação em analisar a organização formal de orações dissociadas de seu contexto de elaboração. Considerando a premissa de que as escolhas feitas pelo usuário da língua não são aleatórias, mas são efetuadas com base nos objetivos comunicativos a que se pretende chegar, objetivamos investigar como os componentes de transitividade dos processos materiais se encontram codificados em contextos discursivos específicos e quais significados são construídos a partir dessas configurações, levando-se em conta os propósitos comunicativos do gênero em questão - a notícia jornalística.

Dessa busca por compreender como as diferentes configurações do sistema de transitividade auxiliam na construção dos sentidos das notícias jornalísticas, pretendemos responder aos seguintes questionamentos: (i) Que tipos de arranjos léxico-gramaticais predominam nas orações que codificam os processos materiais constitutivos das notícias analisadas? (ii) De que forma essa proeminência se relaciona com as funções sociocomunicativas desse gênero discursivo? (iii) Quais as configurações formais e semânticas das expressões que exercem os papéis de participantes das orações materiais? (iv) Quais as razões discursivotextuais para esses modos de realização?

Em virtude do interesse em se conhecerem as diversas configurações que processos do tipo material podem assumir no uso efetivo da linguagem, buscamos a seleção mais sistemática de critérios descritivos capazes de estabelecer as similaridades e dissimilaridades das construções linguísticas, tendo em conta seus aspectos léxico-gramaticais e pragmático-discursivos. Apesar de o tema da transitividade ocupar uma posição de grande relevância nos estudos sistêmico-funcionais, não foram encontradas pesquisas que se dirigissem para essa sistematização. Assim sendo, visando a uma descrição simultânea dos processos e de seus componentes discursivos, selecionamos oito parâmetros descritivos, 
com base no arsenal teórico da Gramática Sistêmico-Funcional e em outras teorias linguísticas, como a Semântica e a Linguística Cognitiva.

O reconhecimento dos modelos e dos padrões de transitividade dos textos selecionados foi feito por Rede Neural de Mapas AutoOrganizáveis. Criado por Teuvo Kohonen, em 1982, esse modelo de inteligência artificial é mais uma importante ferramenta disponível para organização de dados, com a notável característica de representar visualmente a classificação e a distribuição das amostras, por meio de seu posicionamento espacial em um mapa topológico.

Para a descrição dos padrões de transitividade, foram selecionados 31 textos pertencentes ao gênero notícia jornalística. As notícias foram retiradas do banco de dados do corpus VARPORT, disponível no endereço eletrônico www.letras.ufrj.br/varport.

A escolha pelo gênero notícia jornalística baseou-se, primeiramente, na hipótese de que o sistema de transitividade recebia, nesse contexto específico de interação, codificações bastante particulares, em função dos propósitos sociocomunicativos desse gênero discursivo. Uma análise prévia de manchetes presentes nas notícias jornalísticas corroborou essa conjectura, o que motivou uma análise mais criteriosa de textos pertencentes ao gênero em questão.

\section{Quadro teórico: a transitividade na LSF}

Neste estudo, a transitividade é concebida a partir dos pressupostos teóricos da vertente do funcionalismo linguístico denominada Linguística Sistêmico-Funcional (LSF). Dessa feita, com vistas a descrever a importância desse sistema no processo de construção dos significados nas situações reais de uso da língua, além do critério léxico-gramatical, esse fenômeno linguístico é considerado em suas dimensões discursivas e pragmáticas.

Para a LSF, as diferentes redes sistêmicas codificam diferentes espécies de significado, ligando-se, pois, às diferentes funções da linguagem - as chamadas metafunções (ideacional, interpessoal e textual). O sistema de transitividade, por meio dos elementos que o compõem, explica, de forma mais geral, como os fenômenos do mundo real são representados como estruturas linguísticas, ligando-se, portanto, à função ideacional. 
Para muito além da familiar dicotomia entre verbos transitivos e intransitivos, os papéis principais do sistema de transitividade - a saber, os processos, os participantes e as circunstâncias - fornecem o quadro de referência para que a experiência da realidade seja interpretada. O termo processo diz respeito à categoria responsável por codificar ações e eventos, estabelecer relações, exprimir ideias e sentimentos, construir o dizer e o existir; o termo participante diz respeito aos elementos envolvidos com os processos, de forma obrigatória ou não; o termo circunstância refere-se às informações adicionais atribuídas aos processos. A interpretação tripartida dos processos corresponde, genericamente, à distinção gramatical de classes de palavras em verbo, substantivo e advérbio, que permitem analisar quem faz o quê, a quem e em que circunstâncias.

Diferentemente do que se poderia imaginar, se considerado terminologicamente, o sistema de transitividade apresentado pela Gramática Sistêmico-Funcional (GSF) constrói o mundo da experiência por meio de um conjunto relativamente pequeno de processos, que são: os materiais, os mentais, os relacionais, os verbais, os comportamentais e os existenciais. Halliday (1994) explica que os três principais processos do sistema de transitividade são os materiais, os mentais e os relacionais, que codificam, respectivamente, a experiência exterior (ações e eventos), a experiência interior (consciência) e as relações que são estabelecidas entre um fragmento da experiência com outro. Os processos verbais, comportamentais e existenciais estão nas fronteiras entre os principais, preservando certos traços dos processos que os cercam, por isso são considerados secundários.

A seguir, são fornecidas caracterizações bastante gerais dos seis tipos de processo, e são apresentados os participantes que se associam a cada tipo (HALLIDAY, 1994; HALLIDAY; MATHIESSEN, 2004).

Os processos materiais são processos do 'fazer' e do 'acontecer', pois estabelecem uma quantidade de mudança no fluxo do evento. Os participantes associados a esse tipo de processo são, por exemplo, o Ator - aquele que, no evento prototípico, provoca a ação, como em $O$ leão saltou, ${ }^{2}$ em que O leão é o participante Ator; a Meta - aquele para quem a ação é dirigida, ou seja, aquele que efetivamente é modificado pela

\footnotetext{
${ }^{2}$ Os exemplos em itálico, citados nesta seção, são traduções livres de Halliday (1994, p. 109-141) e Halliday e Matthiessen (2004, p. 268-276).
} 
ação, como em O leão pegou o turista, em que o turista é o participante do tipo Meta; o Escopo - o participante que completa e especifica a ação, mas que não é afetado por ela, como na expresssão João tocava piano, em que piano é o Escopo; e o Beneficiário - entidade para quem alguma coisa é feita, criada ou transformada, como em Eu dei ao meu amor um anel, em que ao meu amor é o participante Beneficiário.

Os processos mentais são processos que expressam a apreciação humana do mundo, ou seja, são relativos à representação do nosso mundo interior: desejos, crenças e valores. Os participantes que se associam aos processos mentais são o Experienciador - aquele que sente, pensa, deseja ou percebe, e o Fenômeno - o fato que é percebido, sentido ou compreendido. Em Eu acredito em você, Eu codifica o participante Experienciador, e em você, o participante Fenômeno.

Os processos relacionais são aqueles que estabelecem uma conexão entre entidades, identificando-as ou classificando-as, são os processos de ser, ter e pertencer. Segundo a teoria sistêmica, todas as línguas acomodam, em sua gramática, formas sistemáticas de construção dos processos relacionais, e os tipos principais são: Intensivo (' $\mathrm{X}$ é A'), Circunstancial ('X está em A') e Possessivo ('X tem A'). Os participantes que se associam aos processos relacionais são, por exemplo, o Portador, ou elemento classificado, e o Atributo, ou elemento classificador, como em Sarah é inteligente, em que Sarah codifica o Portador, e inteligente codifica o Atributo.

Os processos verbais são processos que expressam o dizer, e seus participantes são chamados de Dizente - participante inerente que diz, comunica ou aponta algo; Receptor - participante para quem o processo verbal se dirige, e Verbiagem - participante que codifica o que é comunicado. Em O gerente esboçará seu plano de campanha, por exemplo, $O$ gerente codifica o Dizente e seu plano de campanha representa a Verbiagem.

Os processos comportamentais são ações, tipicamente humanas, que englobam os comportamentos físicos e psicológicos, como olhar, assistir, respirar, preocupar-se. A esse tipo de processo estão associados os participantes Comportante - participante consciente que realiza a ação, e Fenômeno - participante que define o escopo do processo.

Por último, mas não menos importantes, estão os processos existenciais, que representam algo que existe ou acontece. Esse tipo de 
processo possui apenas um participante, o Existente, entidade que existe (pessoas, objetos, instituições, eventos etc.).

Quanto às circunstâncias, o terceiro componente do sistema de transitividade, estas exercem a função de definir o contexto no qual uma ação acontece. São realizadas gramaticalmente por grupos adverbiais e ocorrem livremente em todos os tipos de processo. A seguir, descrevemse algumas circunstâncias elencadas por Halliday e Matthiessen (2004).

1. Expansão: Localização e Extensão - constroem o desdobramento do processo em espaço e tempo, como em andar sete milhas e levantar às seis horas.

2. Modo: constrói a maneira pela qual o processo é atualizado, como em Morgan calmamente observava a paisagem do topo de Rock Island, em que a circunstância de modo está representada pelo elemento calmamente.

3. Causa: constrói a razão pela qual o processo é atualizado, como em Assad morreu de insuficiência cardíaca, representada pelo termo de insuficiência cardíaca.

4. Acompanhamento: é uma forma de juntar participantes no processo. Representa o significado de adição, por meio das expressões $e$ e com, ou de subtração, por meio da preposição sem. Um exemplo de circunstância de acompanhamento seria a expressão com meu pai em Eu estava viajando pela costa oeste da Flórida com meu pai.

5. Papel: constrói os significados de ser e tornar-se circunstancialmente. Essa categoria corresponde ao Atributo ou Valor das cláusulas relacionais intensivas. Um exemplo da circunstância de papel seria como socialistas em: Como socialistas, entendemos muito bem o impacto dos cortes de pessoal.

Com base nesses pressupostos da abordagem sistêmica, entendese que os três componentes do sistema de transitividade (processo de desdobramento através do tempo, participantes envolvidos no processo e circunstâncias associadas aos processos) são organizados em configurações que fornecem os modelos ou esquemas para interpretar nossa experiência acerca do que se passa (HALLIDAY; MATTHIESSEN, 2004). A acepção de transitividade adotada pela GSF é, portanto, a de uma propriedade de elaboração de sentidos, no desenvolvimento efetivo da linguagem. 


\section{Percurso metodológico}

O reconhecimento dos padrões de transitivdade dos processos materiais que compõem as notícias jornalísticas contou, fundamentalmente, com duas etapas metodológicas. Essas etapas abarcaram (i) a seleção de critérios descritivos mais sistemáticos e (ii) a submissão dos dados à Rede Neural de Mapas Auto-Organizáveis.

Nosso intento de caracterizar as escolhas feitas, no âmbito do sistema de transitividade, para a elaboração dos sentidos nas notícias jornalísticas, levou-nos à busca por parâmetros descritivos capazes de estabelecer as diferenças existentes entre os processos de natureza material. Assim sendo, com vistas à melhor caracterização das orações materiais e de seus componentes pragmático-discursivos, elaboramos um modelo descritivo, formado por oito parâmetros.

O modelo descritivo foi estabelecido por nós com base, especialmente, na análise criteriosa e sistemática das diferentes codificações dos processos materiais presentes em nosso corpus. Essa análise encontrou embasamento na GSF, nos componentes de transitividade elencados por Hopper e Thompson (1980) e em outros pressupostos adicionais, como a teoria dos papéis temáticos, de Fillmore (1968), o modelo de divisão verbal de Chafe (1979) e alguns pressupostos da Linguística Cognitiva, como a noção de metonímia. Os oito parâmetros selecionados como critério descritivo-metodológico são os seguintes:

1. Caracterização dos fazeres transitivos e intransitivos (TRI) esse parâmetro objetiva diferenciar uma mudança que se estende a um segundo participante, ou seja, a um participante do tipo Meta, de uma mudança que fica confinada ao próprio participante inerente, ou seja, ao Ator. As classes definidoras desse parâmetro são, respectivamente: (i) fazeres transitivos e (ii) fazeres intransitivos.

2. Número de participantes na oração (NUP) - esse parâmetro objetiva identificar a quantidade de participantes envolvidos no processo, a atuação de cada um no desenrolar do evento e as características léxicogramaticais desses participantes. As classes definidoras desse parâmetro são: (i) orações com apenas um participante (Ator); (ii) orações com dois participantes (Ator e Meta, ou Ator e Escopo) e (iii) orações com três participantes (Ator, Meta e Beneficiário).

3. Natureza dos processos materiais (NAP) - por meio desse parâmetro, distinguem-se os fazeres abstratos dos fazeres concretos. Suas 
classes são, portanto, as seguintes: (i) eventos mais abstratos (ideológicos, por exemplo) e (ii) eventos mais concretos.

4. Tipos de "fazeres" materiais (TIF) - baseado no modelo de divisão verbal proposto por Chafe (1979), esse parâmetro objetiva caracterizar as diversas faces que os processos materiais, ou seja, os processos de mudança podem assumir. As classes que compõem esse parâmetro são: (i) ação, (ii) ação-processo e (iii) processo (acontecimento).

5. Propriedades semânticas do Ator (PSA) - esse parâmetro objetiva apontar as diversas funções que a macrofunção Ator pode assumir, por meio da identificação das propriedades semânticas atribuídas a essa categoria. Foram identificadas as seguintes propriedades, que, portanto, compõem as classes desse parâmetro: (i) Ator [+instigador, +controlador] - agente prototípico; (ii) Ator [+/-instigador, +/-controlador] - agente "híbrido"; (iii) Ator [+instigador, -controlador] - entidade causativa; e (iv) Ator [-instigador, -controlador] - entidade mais afetada (típica dos processos do 'acontecer').

6. Formas de expressão do significado (FES) - esse parâmetro objetiva diferenciar as formas de expressão mais congruentes do significado daquelas menos congruentes, ou seja, daquelas em que o locutor atribui novas funções aos componentes do sistema de transitividade. Esse parâmetro é constituído pelas seguintes classes: (i) expressões congruentes; (ii) expressões metafóricas e (iii) expressões metonímicas do significado.

Diferentemente da tradição literária, que sempre concebeu as expressões metafóricas e metonímicas como meras figuras de linguagem, neste trabalho, à luz dos estudos sistêmicos e cognitivistas, essas concepções assumem um novo status. As expressões metafóricas do significado (ou metáforas gramaticais) estão sendo consideradas como um processo em que uma nova expressão do significado surge em função de uma nova atribuição de papéis no âmbito do sistema léxicogramatical. Em nosso corpus, foram identificados os seguintes processos metafóricos: (i) um termo congruentemente circunstancial é codificado como um participante do tipo Ator (DAMASCENO et al., 2014) e (ii) um grupo nominal que congruentemente exerce a função de Meta nas orações transitivas é estruturado como um participante Ator nas orações intransitivas (estruturas ergativas). Já as expressões metonímicas estão sendo concebidas como um processo cognitivo, em que uma entidade conceitual (o ponto de referência) proporciona acesso mental para outra 
entidade conceitual (o alvo desejado). De acordo com as relações que expressam, as metonímias são classificadas em diversos tipos (LAKOFF; JOHNSON, 2007, p. 76). Em nosso corpus, foram encontradas relações metonímicas dos tipos instituição pelos responsáveis e lugar pela instituição.

7. Objetivos pragmático-discursivos das configurações oracionais $(O P D)$ - as diversas configurações atribuídas à oração, por meio da manipulação dos componentes do sistema de transitividade, encontram-se atreladas a objetivos discursivos bastante relevantes no contexto das notícias jornalísticas. Cumpre a esse parâmetro descrever esses objetivos, tendo em vista as escolhas efetuadas pelo usuário na codificação dos eventos relatados. Foram considerados cinco objetivos principais, que constituem as classes desse parâmetro: (i) individualização do participante responsável pelas mudanças; (ii) generalidade (a agentividade é atribuída a toda a espécie) ${ }^{3}$ (iii) indefinição da entidade agentiva; (iv) tematização (um elemento causal, por exemplo, é elevado à posição de Tema da mensagem, mas a entidade agentiva pode ser recuperada no corpo da notícia) e (v) ocultação da entidade responsável pelas mudanças.

8. Expansão dos processos materiais (EXP) - em adição aos participantes inerentes das orações intransitivas (Ator) e transitivas (Ator e Meta), há, em alguns casos, outros papéis e algumas circunstâncias envolvidas nas construções do tipo material. Assim, por meio desse parâmetro, buscamos identificar os termos que expandem o significado das orações materiais. Conforme prevê a teoria sistêmica, esses elementos de expansão podem ser de três tipos, de acordo com as relações lógicosemânticas que estabelecem: elaboração, extensão e realce (HALLIDAY; MATTHIIESSEN, 2004, p. 189). Considerando o uso efetivo dessas expansões nos dados deste estudo, chegamos a um total de seis diferentes classes: (i) orações sem expansão; (ii) expansão por extensão; (iii) expansão por elaboração; (iv) expansão por realce; (v) expansão por extensão e realce, concomitantemente e (vi) expansão por elaboração e realce, concomitantemente.

Embora tenham se revelado bastante eficientes na descrição do nosso corpus, os oito parâmetros estabelecidos não constituem um

\footnotetext{
${ }^{3} \mathrm{O}$ termo espécie está sendo usado no sentido de grupos de entidades definidas culturalmente mediante alguma propriedade comum (MÜLLER, 2003).
} 
modelo de análise encerrado em si mesmo, pois reconhecemos que, consideradas as especificidades dos dados e as intenções das análises, outros parâmetros e outras classes podem ser acrescentados a essa listagem.

Definidos os critérios descritivos, os dados que compõem o corpus deste estudo foram submetidos à Rede Neural de Mapas Auto-Organizáveis, um modelo estatístico de inteligência artificial especialmente elaborado para o reconhecimento de padrões.

O agrupamento de informações constitui-se uma tática indispensável na produção de conhecimento, pois, por intermédio dessa estratégia, a identificação de padrões e de características de determinados dados se torna possível. Os Mapas Auto-Organizáveis (Self-organizing Maps - SOM) são mais um dos importantes algoritmos disponíveis para organização de informações, com a importante característica de representarem visualmente a classificação e a distribuição dos dados, através de seu posicionamento espacial em uma rede ou grade.

A concepção de Mapas Auto-Organizáveis como modelo neural é motivada por uma característica distintiva do cérebro humano: estudos biológicos têm demonstrado que as células do córtex cerebral se organizam de forma altamente estruturada em suas funções, resultando em regiões do cérebro especificamente capacitadas no processamento sensorial, como visão, audição, controle motor, linguagem etc. (KOHONEN, 2001). As diferentes entradas sensoriais são representadas, portanto, por mapas computacionais ordenados topologicamente. O mapa computacional constitui um bloco construtivo básico na infraestrutura de processamento de informação do sistema nervoso (HAYKIN, 2001).

Semelhantemente ao que ocorre no modelo cerebral humano, no modelo estatístico de Kohonen (KOHONEN, 1982; 1990), os dados de entrada, por meio de aprendizado competitivo e não supervisionado, são mapeados em um conjunto finito de neurônios (nodes) organizados em uma grade ( $\mathrm{grid}$ ), normalmente bidimensional. Os modelos mais semelhantes estão associados a neurônios próximos na grade, e modelos menos similares são posicionados, gradualmente, em neurônios mais distantes na grade.

De acordo com Kohonen (2013), os princípios matemáticos e de aprendizagem na Rede Neural de Mapas Auto-Organizáveis (doravante, Rede SOM) podem ser entendidos da seguinte forma: cada vetor de entrada (input vector) seleciona o modelo localizado no neurônio que 
melhor corresponda às suas características, e isso se repetirá com os demais vetores de entrada. Dessa forma, vetores mais semelhantes serão posicionados em neurônios próximos, formando sua vizinhança. A Figura 1, exibida adiante, ilustra os elementos principais que norteiam a Rede SOM.

Haja vista a Figura 1 e as informações apresentadas até o momento, apreende-se que o mapa de grade é, portanto, previamente montado e organizado com os respectivos modelos relacionados aos neurônios. Os vetores de entrada serão recebidos nos neurônios associados aos modelos vencedores (definidos pelo cálculo da menor distância euclidiana). A construção da grade possibilita a inspeção rápida e fácil das relações de similaridade dos dados de entrada, bem como da sua tendência de agrupamento.

FIGURA 1 - Rede Neural de Mapas Auto-Organizáveis: visualização tridimensional

Mapa de grade
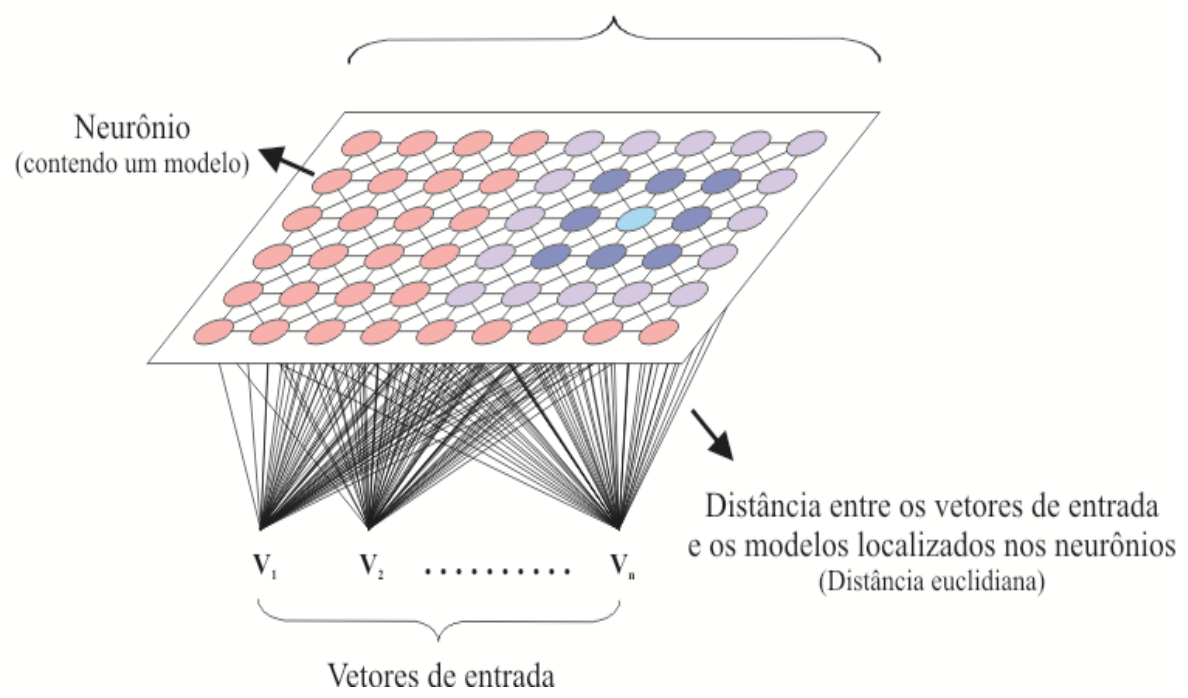

Fornecidas as características gerais da Rede SOM, descrevemos, a partir de agora, as principais etapas dos procedimentos de análise por 
Rede Neural não supervisionada via algoritmo SOM (KOHONEN, 1982). As análises estatísticas foram realizadas no Programa $\mathrm{R}$ versão 3.1.2 (R DEVELOPMENT CORE TEAM, 2011), por meio do pacote "kohonen" (WEHRENS; BUYDENS, 2007).

Inicialmente, os dados obtidos foram escalonados de acordo com a função "scale( )", disponível no Programa R. Visto que os parâmetros possuem quantidades diferenciadas de classes, o objetivo do escalonamento foi conceder a mesma importância a cada uma das classes dos parâmetros, durante o processamento na Rede SOM. Essa estratégia possibilita a análise dos dados de forma mais gradiente, pois não requer um número de categorias comum a todos os parâmetros (como requer, por exemplo, o modelo proposto por Hopper e Thompson (1980), em que a atribuição de valores é de 0 e 1 , somente).

A Rede Neural utilizada foi idealizada a partir de uma matriz de entrada de 131 x 8, correspondendo, respectivamente, ao número de estruturas analisadas (131) e à quantidade de parâmetros (8). Cada vetor de entrada utilizado para alimentar a Rede foi constituído pelos valores atribuídos às classes dos parâmetros, aplicados a cada uma das orações que compõem o corpus do trabalho.

De acordo com Kohonen (2013), o tamanho do grid map é, via de regra, definido pelo método de tentativa e erro, não sendo possível adivinhar ou estimar, antecipadamente, seu tamanho exato. Sendo assim, a configuração do mapa topológico da Rede SOM foi definida após sucessivas tentativas. Com essas tentativas, buscou-se, sempre, minimizar o erro topológico, para que fosse selecionado um mapa de maior qualidade (ou seja, um mapa que retratasse mais fidedignamente as similaridades e dissimilaridades dos dados, tendo em vista sua distribuição na grade). O erro topológico expressa a capacidade da Rede SOM de representar a disposição dos dados no mapa de grade.

Seguida à estruturação do grid map, a Rede SOM foi treinada, com o objetivo de se obter a melhor precisão possível com relação aos modelos localizados dentro dos neurônios. Nesse treinamento, foram utilizados a taxa de aprendizagem, o raio topológico da vizinhança e o número de iterações previamente definidos no modelo estatístico disponível no pacote "kohonen" do Programa R (ou seja, optamos por não alterar a configuração sugerida no pacote).

O treinamento da Rede SOM objetivou, ainda, alcançar a menor distância média entre os modelos dos neurônios e os vetores de entrada. 
Com essa distância minimizada, os modelos dos neurônios retratam mais fielmente as diferentes codificações dos processos materiais quanto aos parâmetros selecionados.

Com o intuito de descrever os padrões de transitividade mais significativos nos textos analisados, estimamos, por meio do pacote clValid (BROCK et al., 2008), o número ótimo de grupos. A definição estatística dos agrupamentos possibilitou que as orações que compõem o corpus deste estudo fossem congregadas a partir de critérios bem definidos, o que revelou aspectos bastante relevantes com relação aos modelos de transitividade.

As seções subsequentes, que apresentam os resultados encontrados, permitem visualizar, de forma mais efetiva, as implicações desse protocolo de processamento sobre a descrição do sistema de transitividade dos processos materiais que compõem as notícias jornalísticas.

\section{Padrões de transitividade de processos do tipo material e os significados construídos no contexto de notícias jornalísticas}

Tendo como referência a relação de similaridade entre os sinais de entrada, ou seja, entre as classes que compõem os oito parâmetros selecionados, as 131 orações constitutivas do corpus deste estudo foram alocadas pela Rede SOM em 44 neurônios distintos, num grid map formado por 121 neurônios (11 x 11). A Figura 2, a seguir, de natureza bidimensional, demonstra como os dados de entrada foram distribuídos sobre o grid map e proporciona a identificação dos modelos formados a partir da semelhança entre esses dados. 
FIGURA 2 - Modelos de transitividade dos processos materiais, a partir da relação de similaridade entre as classes que compõem os oito parâmetros descritivos selecionados

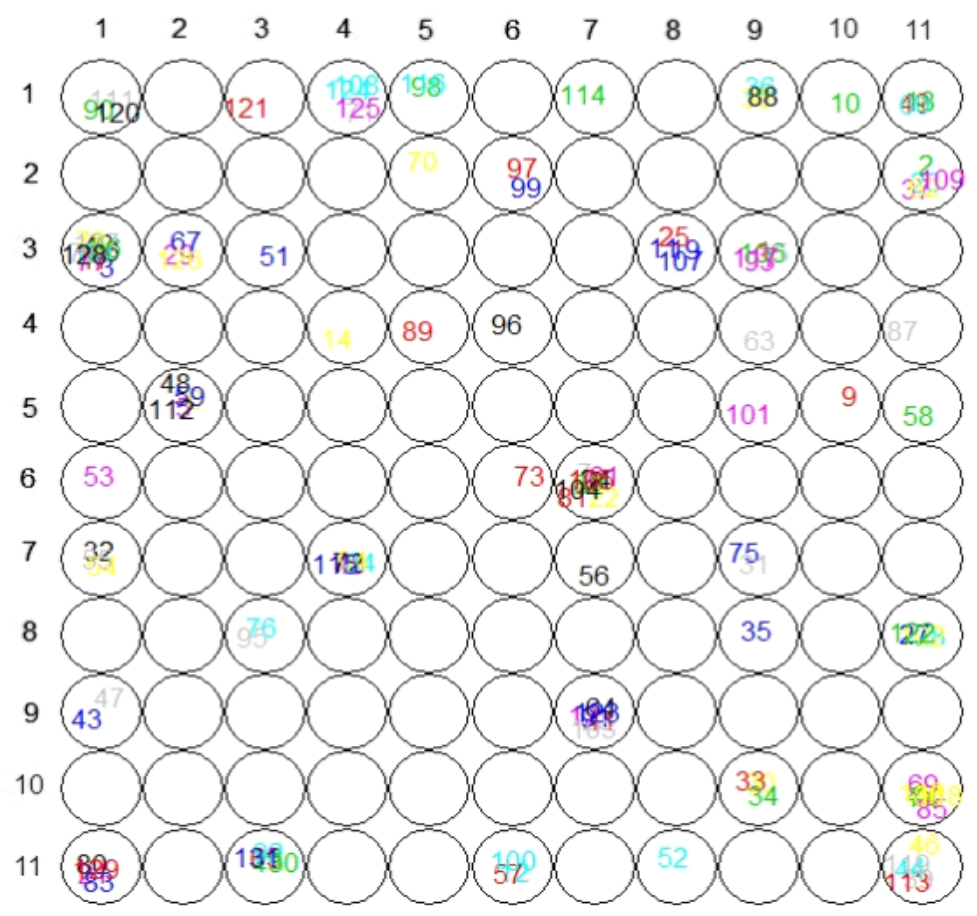

A finalidade da Figura 2 é exibir, de forma genérica, o modo de organização dos dados sobre o mapa topológico. Na figura em questão, os neurônios efetivamente preenchidos retratam os modelos de transitividade encontrados nas notícias jornalísticas, conforme mostraremos mais detalhadamente a seguir.

Temos dito que o objetivo principal dos Mapas Auto-Organizáveis é aproximar os dados de entrada que são semelhantes entre si, formando agrupamentos e padrões. A título de exemplificação, apresentamos as orações que compõem o neurônio 22 do mapa correspondente à Figura 2. As estruturas consideradas neste momento são aquelas construídas com os verbos afundar, chegar, explodir e repicar: 


\section{Neurônio 22 (linha 2, coluna 11)}

Oração $2^{4}$ - Passados dez anos do naufrágio do "Bateau Mouche IV", que afundou na Baía de Guanabara no réveillon de 1988 matando 55 pessoas, dois de seus donos, foragidos da Justiça brasileira, vivem e trabalham normalmente na Espanha. (E-B-94-Jn-031)

Oração 20 - Urna eletrônica chega a interior do estado. (E-B-94Jn-027)

Oração 62 - A bomba explodiu no colo do sargento. (E-B-94-Jn-013)

Oração 109 - Quando Ulysses Guimarães declarar promulgada a Constituição, a oitava na história do Brasil, e a quarta emanada de um legítimo poder constituinte, os sinos repicarão em todo o país. (E-B94-Jn-019)

Considerados os oito parâmetros de descrição, anteriormente apresentados, as estruturas linguísticas que compõem esse neurônio 22 seguem o seguinte padrão léxico-gramatical e discursivo:

(i) São do tipo intransitivas, visto que a mudança não se estende a um segundo participante, mas fica confinada ao próprio participante Ator.

(ii) Possuem apenas um participante (o Ator).

(iii) Representam processos materiais mais perceptíveis aos sentidos, portanto, mais concretos.

(iv) Expressam acontecimentos, portanto, são orações processuais.

(v) Codificam um participante Ator menos agentivo.

(vi) Encerram um sentido mais metafórico do significado, visto que o participante instaurado como o Ator do processo possui as características prototípicas de um participante do tipo Meta, quais sejam: [-volitivo, -instigador, +afetado].

(vii) Têm a ocultação da entidade agentiva como um objetivo pragmático-discursivo.

(viii) Possuem circunstâncias de localização como elemento de expansão do processo (expansão do tipo realce).

\footnotetext{
${ }^{4} \mathrm{Na}$ Figura 2, os números indicados dentro dos neurônios não correspondem à sequência de apresentação dos exemplos ao longo do trabalho.
} 
Assim como o neurônio 22, todos os demais neurônios formados pela Rede SOM, conforme Figura 2, possuem um elevado grau de regularidade com relação ao conjunto das classes dos parâmetros. Sendo assim, foi possível identificar, no contexto das notícias jornalísticas, quarenta e quatro diferentes modelos de codificação dos processos materiais, considerando, concomitantemente, alguns aspectos léxicogramaticais e pragmático-discursivos, selecionados aqui como as propriedades relevantes para a descrição do sistema de transitividade.

Por meio dos Mapas Auto-Organizáveis, é possível vislumbrar, ainda, os modelos de construção mais recorrentes nas notícias jornalísticas. Os neurônios destacados pelas cores vermelha e amarela da Figura 3, a seguir, foram os que reuniram o maior número de estruturas (doze e nove, respectivamente).

FIGURA 3 - Quantidade de orações em cada neurônio. ${ }^{5}$

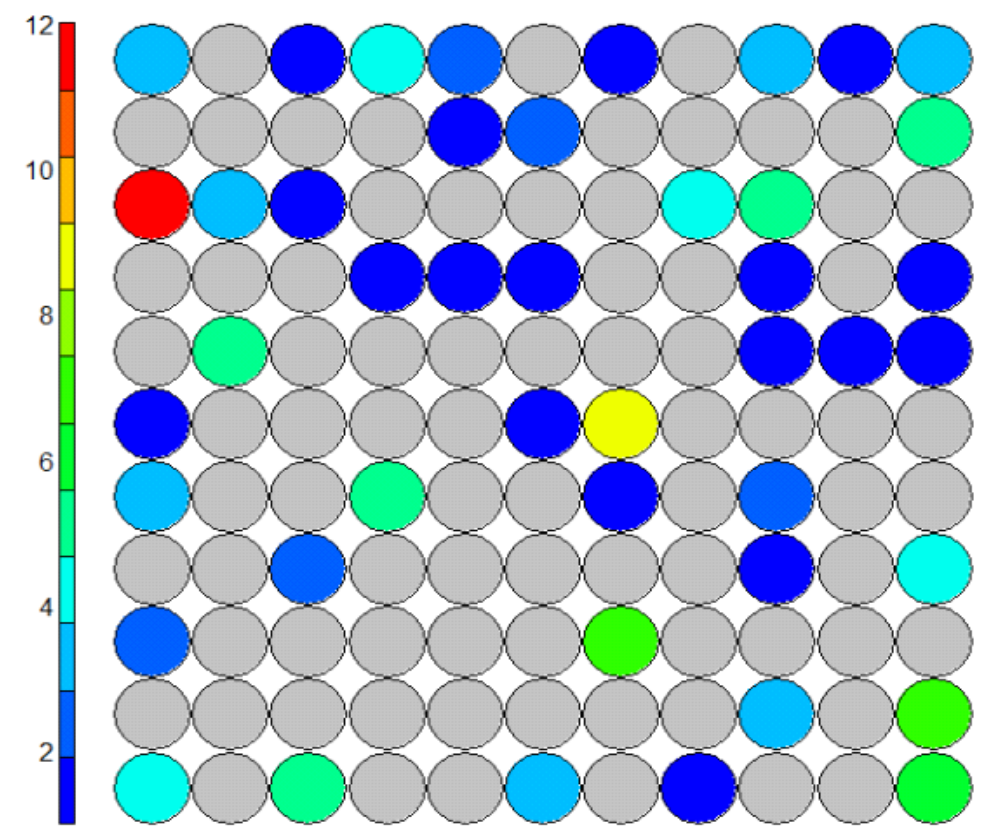

\footnotetext{
${ }^{5}$ Os neurônios vazios, ou seja, os modelos que não tiveram orações que os representassem, são indicados pela cor cinza.
} 
O modelo de transitividade mais recorrente nas notícias jornalísticas, representado na Figura 3 pelo neurônio em vermelho, possui as seguintes características:

(i) Os fazeres são intransitivos, ou seja, a mudança não se estende a um participante do tipo Meta.

(ii) As orações possuem apenas um participante, o Ator.

(iii) Os processos codificados são mais concretos.

(iv) As orações denotam uma ação.

(v) O Ator é um agente prototípico, ou seja, é uma entidade [+instigadora, +controladora].

(vi) A expressão do significado é mais congruente.

(vii) O participante Ator é representado por SNs com nome próprio, ou seja, o responsável pela ação é plenamente identificável (individualização).

(viii) O evento é situado no espaço e/ou no tempo, por meio de grupos adverbiais (expansão por realce).

Como exemplos desse modelo de transitividade, citamos as orações elaboradas com os verbos entrar e $i r$ :

[01] Mohamed Ali Agca, 23 anos, entrou na Itália há duas semanas, vindo da Espanha, desembarcando em Milão. (E-B94-Jn-012)

[02] Frei Beto atendeu a todos os telefonemas e recebeu a secretária de Lula, D. Ivonete, que foi lá à procura de instruções. (E-B-94-Jn-008)

Ainda de acordo com a Figura 3, constatamos que o neurônio 62 (em amarelo) reuniu o segundo modelo mais recorrente nas notícias jornalísticas. Os dados alocados nesse neurônio apresentam as seguintes características:

(i) As estruturas possuem um participante do tipo Meta, por isso, são transitivas.

(ii) As orações possuem dois participantes, o Ator e a Meta. 
(iii) Os processos codificados encontram-se no campo das ideologias, portanto, são mais abstratos.

(iv) As orações expressam, concomitantemente, uma ação e um processo (ação-processo).

(v) O Ator é um agente híbrido, ou seja, possui as seguintes propriedades semânticas: [+/-instigador, +/-controlador].

(vi) Opta-se pela expressão metonímica do significado, como a relação instituição pelos responsáveis.

(vii) O Ator é representado por SNs lexicais e o real agente da mudança ocupa um plano secundário. A responsabilidade pela ação é atribuída a organizações empresariais, sociais e políticas (indefinição).

(viii) Circunstâncias de modo, de localização temporal e de localização espacial expandem o significado dos processos (expansão por realce).

Como exemplos desse segundo modelo de transitividade, apresentamos as orações construídas com os verbos arquivar e rejeitar:

[03] STM (Superior Tribunal Militar) arquiva Riocentro em definitivo por 10 a 4. (E-B-94-Jn-013)

[04] Ao final de mais de 60 discursos, numa das mais longas (16 horas) e tensas sessões de sua história, o Congresso Nacional rejeitou as primeiras horas de hoje, por não ter alcançado quorum constitucional, a emenda Dante de Oliveira, que previa eleições diretas já para a Presidência da República. (E-B-94-Jn-015)

Os modelos de construção mais frequentes nos textos jornalísticos, representados pelos neurônios em vermelho e em amarelo na Figura 3, encontram-se em consonância com os dados quantitativos apurados, em que se observou que as estruturas linguísticas nas notícias jornalísticas, em termos de percentuais, realizam duas principais funções pragmático-discursivas, a saber: a individualização (com $31 \%$ do total de ocorrências) e a indefinição (com $22 \%$ do total de ocorrências). Na individualização, a entidade humana que pratica a ação é referenciada por um SN com nome próprio, o que a torna plenamente identificável. Já na indefinição, na maioria das ocorrências, o fazer é atribuído, por meio de 
processo metonímico, a instituições empresariais ou organizações sociais e políticas. O que se observa a partir dessa confluência de informações é o fato de haver, por parte da notícia, a incumbência maior de, sempre que possível, identificar os responsáveis pelas ações relatadas, seja de forma mais específica, com o uso de nomes próprios (como nos exemplos [01] e [02]), ou de forma mais abrangente, valendo-se do processo metonímico do tipo instituição pelos responsáveis (como nos exemplos [03] e [04]).

Os resultados apresentados na Figura 3 permitem observar que os dois principais arranjos de transitividade encontrados nas notícias jornalísticas coincidem com o propósito comunicativo fundamental desse gênero discursivo, que é o de informar quem fez o quê (a quem), quando, onde e como (LAGE, 2003). Por meio de proposições completas, ou seja, de estruturas que contêm, além do grupo verbal (acompanhado ou não de complemento do tipo objeto), um Ator mais agentivo e grupos circunstanciais, a notícia cumpre a missão de informar, de forma mais efetiva, sobre as transformações efetuadas na sociedade.

Apesar de termos tomado como referência para os apontamentos supracitados os neurônios 23 e 62, portadores dos modelos com maior número de dados, é importante que se ressalte o fato de os Mapas AutoOrganizáveis procurarem fazer com que neurônios próximos entre si no grid map retratem dados próximos entre si no espaço de dados. Sendo assim, com base na similaridade entre os neurônios (rede de vizinhança), para melhor apreensão dos padrões de transitividade codificados nas notícias jornalísticas, os dados deste estudo foram subdivididos em agrupamentos maiores. O número ótimo de grupos foi estabelecido pela metodologia descrita em Brock et al. (2008). Tal metodologia apontou para duas subdivisões ideais: uma que considera os dados em dois grandes agrupamentos, e a outra que subdivide os processos analisados em quinze agrupamentos. A Figura 4, a seguir, proporciona a visualização dos dados sob o enfoque de dois grandes grupos. 
FIGURA 4 - Agrupamento dos dados, segundo Brock et al. (2008)

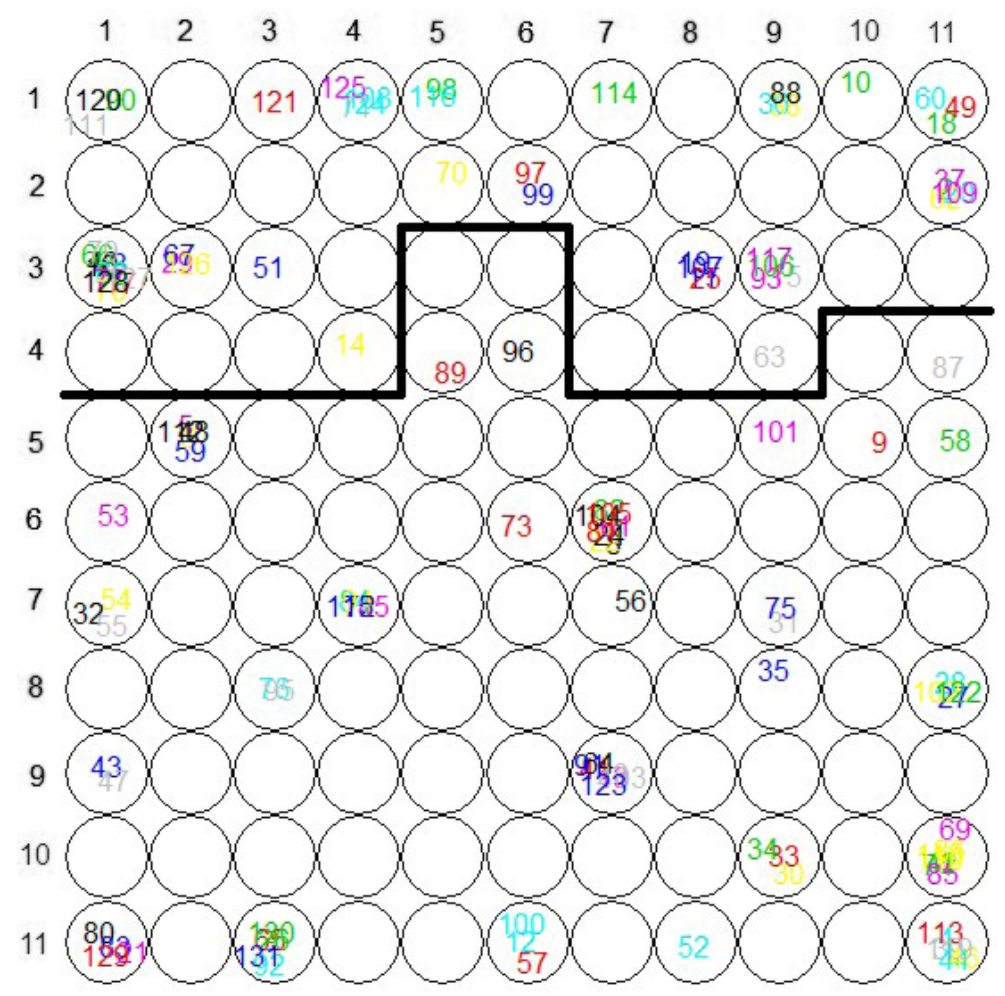

Em termos de classes de parâmetros, os agrupamentos 1 (parte superior da Figura 4) e 2 (partes central e inferior da Figura 4) apresentam significativa diferença: o primeiro reúne somente processos do tipo intransitivo, e o segundo, por sua vez, concentra somente processos do tipo transitivo. Tendo em conta esses agrupamentos maiores, além de considerarmos o modo de organização do sistema de transitividade das construções materiais nas notícias jornalísticas, podemos inferir acerca das particularidades das construções materiais no que tange aos quesitos transitivo e intransitivo.

A diferença entre os processos transitivos e intransitivos pode ser observada, por exemplo, sob o viés da distância espacial entre os neurônios. Essa perspectiva corresponde ao fato de que quanto mais 
próximos os neurônios estiverem no grid map, mais similares eles serão (a proposição contrária também é verdadeira: quanto mais distantes eles estiverem, mais diferentes eles serão). Dessa feita, em termos de similaridade, o neurônio 24 (linha 3, coluna 2), por exemplo, é menos distante do neurônio 25 (linha 3, coluna 3) do que o neurônio 86 (linha 8, coluna 9). Como forma de corroborar essa afirmação, consideremos parte dos dados que compõem esses neurônios. As estruturas tomadas como exemplo foram construídas com os verbos cruzar, entrar e derrotar:

\section{Neurônio 24 (linha 3, coluna 2)}

[05] Pouco depois de o governo da Alemanha Oriental anunciar que decidira abrir todas as suas fronteiras com a Alemanha Ocidental, multidões excitadas já se aglomeravam, em Berlim, nos postos de passagem entre os dois setores da cidade e cruzavam para o outro lado - nem que fosse apenas para fazer um passeio. (E-B-94-Jn-020)

\section{Neurônio 25 (linha 3, coluna 3)}

[06] O Ibama e a Polícia Federal, em operação que mobilizou 70 agentes e fiscais e um helicóptero, entraram na reserva dos índios caiapós, na Serra do Cachimbo (PA), e descobriram um sistema organizado de retirada ilegal de mogno, protegido por oito indígenas armados com carabinas calibre 22. (E-B-94-Jn-028)

\section{Neurônio 86 (linha 8, coluna 9)}

[07] Aprovação da reeleição derrota ao mesmo tempo Maluf, Quércia e Paes de Andrade. (E-B-94-Jn-026)

De fato, quando são consideradas as classes constitutivas dos oito parâmetros, vemos que os neurônios 24 e 25 diferem em apenas dois quesitos (propriedades semânticas do Ator e formas de expressão do significado), enquanto os neurônios 25 e 86 diferem em seis dos oito 
quesitos (fazeres transitivos e intransitivos, número de participantes na oração, natureza do processo, tipos de "fazeres" materiais, propriedades semânticas do Ator e formas de expressão do significado). Em termos de modelo de transitividade o neurônio 24 é, então, mais semelhante ao neurônio 25 que o neurônio 86.

A partir da disposição dos dados na Figura 4, percebemos, portanto, que os neurônios do macroagrupamento 1, formado pelos processos materiais intransitivos, encontram-se, em termos espaciais, menos distantes que os neurônios do macroagrupamento 2, formado pelos processos materiais transitivos. Essa distribuição espacial dos dados no grid map indica que as diferenças existentes entre os modelos que acomodam os processos intransitivos são menos expressivas que as diferenças existentes entre os modelos que reúnem os processos transitivos. Dito de outra forma, considerados simultaneamente os oito parâmetros descritivos, os modelos intransitivos apresentam mais similaridade entre si que os modelos transitivos - o que justifica a concentração dos neurônios intransitivos em um espaço mais compactado no mapa topológico. Dada a importância dessa constatação para os estudos da transitividade, entendemos que essa perspectiva mereça ser averiguada a partir de uma amostra maior de dados, para que conclusões mais efetivas possam ser retiradas a partir desse direcionamento.

Para as discussões subsequentes, consideraremos, a partir de agora, o mapa exibido a seguir, que apresenta um panorama bastante dinâmico de como os dados deste estudo estiveram representados sobre o mapa de grade. 
FIGURA 5 - Representatividade das classes dos parâmetros em cada neurônio

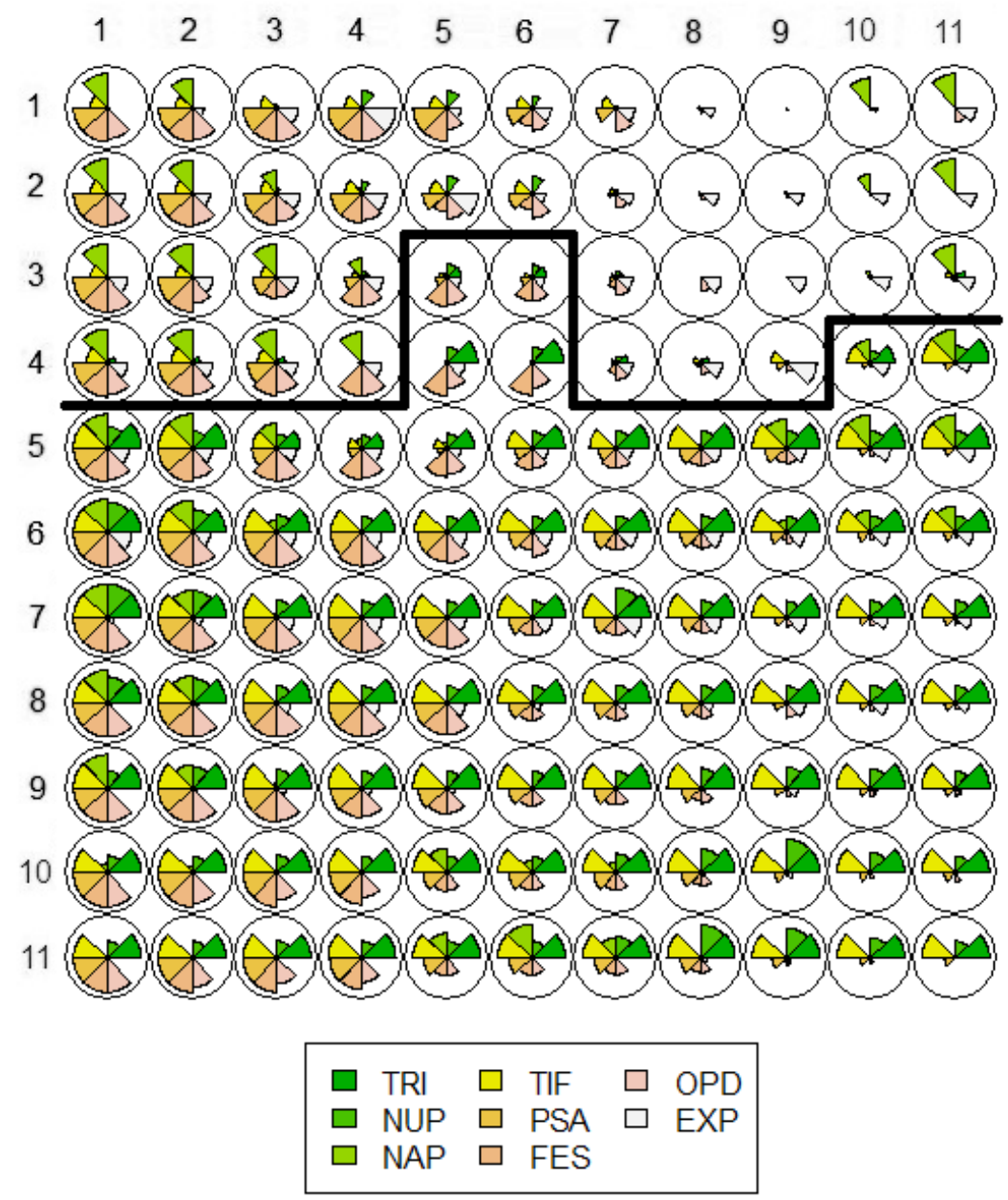

Como a Figura 5 lida, concomitantemente, com todas as propriedades descritivas apresentadas até o momento, retomamos no Quadro 1, a seguir, os oito parâmetros sobre os quais se assentaram as análises feitas neste trabalho, suas devidas abreviações e as classes que compõem cada um desses parâmetros: 
QUADRO 1 - Parâmetros selecionados para descrição dos dados, as classes componentes desses parâmetros e as abreviações adotadas

\begin{tabular}{|c|c|c|}
\hline Parâmetros & Classes & Abreviação \\
\hline Fazeres transitivos e intransitivos & $\begin{array}{c}\text { processos transitivos, processos } \\
\text { intransitivos }\end{array}$ & TRI \\
\hline Número de participantes na oração & Um, dois, três & NUP \\
\hline Natureza do processo & Mais concreta, mais abstrata & NAP \\
\hline Tipos de "fazeres" materiais & Ação-processo, ação, processo & TIF \\
\hline Propriedades semânticas do Ator & $\begin{array}{c}\text { Agente prototípico, agente híbrido, } \\
\text { entidade causativa, entidade menos } \\
\text { instigadora/mais afetada }\end{array}$ & PSA \\
\hline Formas de expressão do significado & $\begin{array}{c}\text { Congruente, metonímica, metafórica } \\
\text { Individualização, generalidade, } \\
\text { Objetivos pragmático-discursivos }\end{array}$ & FES \\
\hline Expansão dos processos materiais & $\begin{array}{c}\text { Não há, elaboração, extensão, realce, } \\
\text { realce/elaboração, realce/extensão }\end{array}$ & EXP \\
\hline
\end{tabular}

O mapa referente à Figura 5 proporciona uma visualização simultânea de como todas as classes que compõem os oito parâmetros descritivos estiveram representadas em cada um dos neurônios presentes no grid map. Em termos gerais, as informações fornecidas nesse mapa devem ser lidas da seguinte forma: quanto mais preenchidos estiverem os gráficos de pizza dentro dos neurônios, mais próximos estarão os modelos representados por esses neurônios de uma codificação material mais prototípica. Como forma de exemplificação, tomemos como referência o neurônio 56 (linha 6 , coluna 1), que contém o gráfico de pizza mais completo, considerando todos os arranjos organizados no grid map. Conforme indicado na Figura 3, esse neurônio acopla uma única oração, construída com o verbo enviar:

[08] Em novembro de 1979, Mohamed enviou uma carta, assinada com seu próprio nome, ao jornal Millyet, de Istambul, anunciando disposição de matar o Papa João Paulo II durante sua visita à Turquia. (E-B-94-Jn-012)

O modelo de transitividade representado pelo neurônio 56 caracteriza-se pelas seguintes propriedades: (i) o fazer é transitivo, pois apresenta um participante do tipo Meta (uma carta); (ii) a oração possui 
três participantes: Ator (Mohamed), Meta (uma carta) e Beneficiário (ao jornal Millyet); (iii) o processo é mais concreto; (iv) a estrutura codifica, simultaneamente, uma ação e um processo (há, portanto, um sujeito agentivo e um objeto afetado); (v) o Ator é representado por um agente prototípico, cujas propriedades são [+instigador, +controlador]; (vi) a expressão do significado é mais congruente; (vii) a entidade fazedora da ação verbal é plenamente identificada (Mohamed) e (viii) o sentido do processo é estendido por meio de uma circunstância de localização temporal (expansão por realce - Em novembro de 1979) e de um participante do tipo Beneficiário (expansão por extensão - ao jornal Millyet).

O fato de o neurônio 56 reunir o maior número de propriedades de um processo material prototípico faz com que ele abrigue um gráfico de pizza mais integral. A ausência de uma fatia do gráfico ou a representação de apenas parte da fatia indica que o neurônio se distancia desse modelo de processo mais discriminativo.

Considerando-se essas informações, a Figura 5 mostra, de modo mais abrangente, que os dados deste estudo foram distribuídos no grid map da seguinte forma:

1. Encontram-se reunidos, no canto superior esquerdo (acima da linha divisória), os fazeres intransitivos mais próximos do protótipo da categoria. Esses modelos foram representados por gráficos de pizza relativamente bem preenchidos.

2. Em contrapartida, no canto superior direito (também acima da linha divisória), encontram-se reunidos os modelos intransitivos mais distantes do protótipo, como os processos com um Ator menos instigador e mais afetado. Esses modelos foram representados por gráficos de pizza muito pouco preenchidos, o que configura esse distanciamento bastante significativo do protótipo dos processos materiais intransitivos.

3. Os neurônios que acoplam os gráficos de pizza mais preenchidos, conforme vemos na Figura 5, estiveram reunidos no lado esquerdo do grid map, nas partes central e inferior da figura. Esses modelos representam os fazeres materiais transitivos mais prototípicos, como as orações com um Ator agentivo e que codificam um significado mais congruente.

4. Em contrapartida, no lado direito da Figura 5, abaixo da linha divisória, foram reunidos os modelos transitivos que se distanciam do protótipo da categoria. Os gráficos de pizza menos preenchidos indicam, 
por exemplo, que o Ator, nessas codificações, exerce um papel menos agentivo e que os significados são expressos de forma mais metafórica.

Em virtude das características dos dados, além dos dois macroagrupamentos já estabelecidos, a Figura 5 permite entrever a necessidade de outas subdivisões, a fim de que os padrões de transitividade sejam mais bem definidos. Aplicamos, então, a estimativa de 15 agrupamentos, conforme indicou a metodologia de Brock et al. (2008). Os quinze novos agrupamentos sintetizam os padrões de transitividade presentes nas notícias jornalísticas. Esses padrões podem ser interpretados a partir da Figura 6, a seguir.

FIGURA 6 - Padrões de transitividade dos processos materiais das notícias jornalísticas

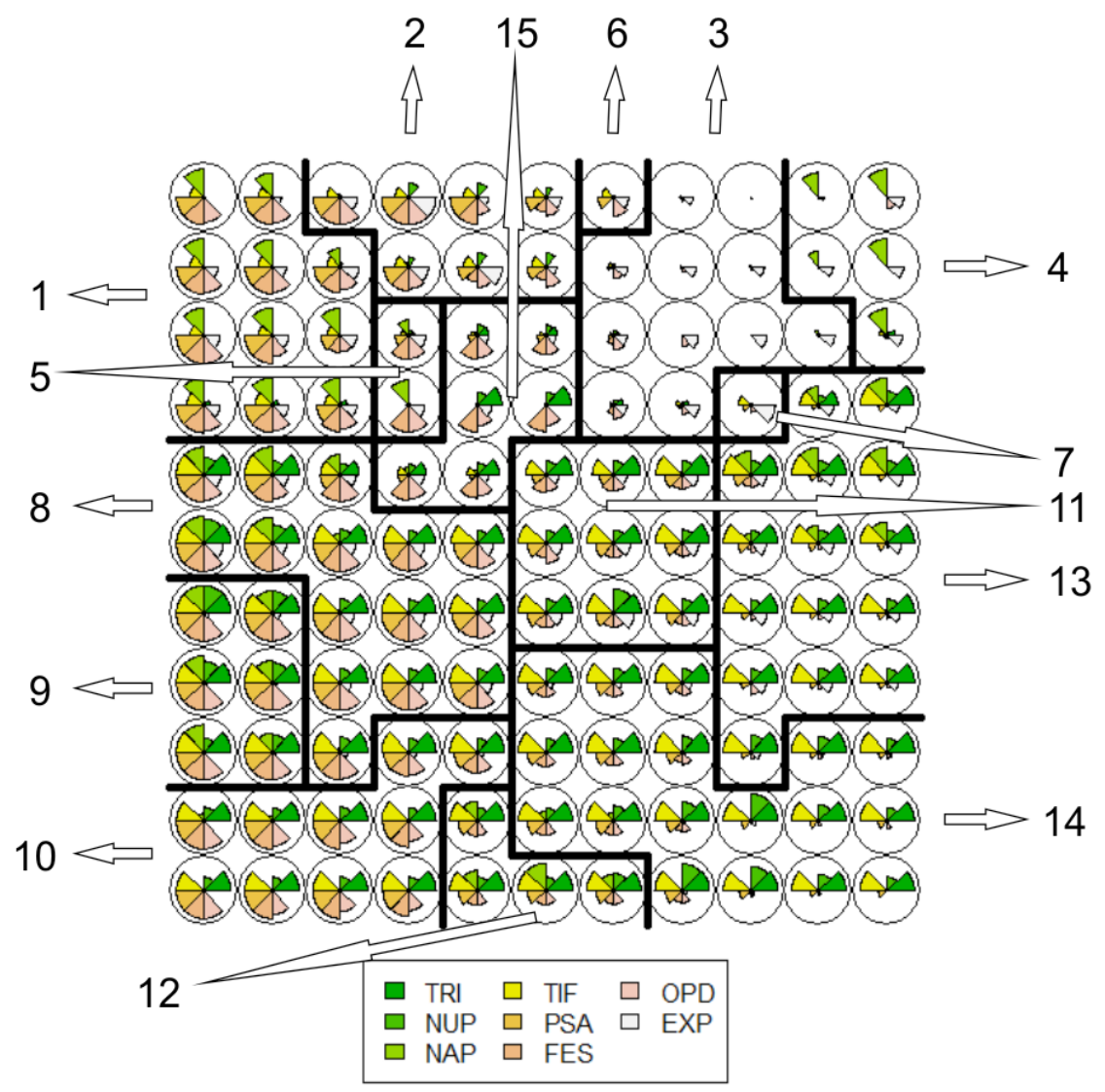


A partir da Figura 6, podemos visualizar os principais padrões concernentes ao sistema de transitividade dos processos materiais transitivos e intransitivos, constitutivos dos textos jornalísticos analisados:

\section{PROCESSOS INTRANSITIVOS}

Padrão 1 - As estruturas tendem a codificar ações realizadas por um Ator mais agentivo, mais humano e mais individualizado. As mudanças efetuadas não se estendem a outro participante, mas incidem sobre o próprio Ator, que é o único participante envolvido no processo. As transformações são mais perceptíveis e, portanto, mais concretas. A realização do processo é situada no tempo e/ou no espaço.

Como exemplo desse padrão de transitividade, citamos a oração construída com o verbo descer:

[09] Em seguida, o General [Newton Cruz] desceu de seu gabinete, bastão de comando em punho, apreendeu cerca de 100 automóveis e sete ônibus. (B-94-Jn-015)

Padrão 2 - Com um Ator mais agentivo (prototípico ou híbrido), as estruturas com esse arranjo de transitividade possuem dois participantes. No entanto, as mudanças efetuadas não se estendem ao segundo participante (que é do tipo Escopo), mas se atêm ao próprio Ator. O segundo participante, nesse tipo de construção, exerce a função de especificar o domínio (ou a esfera) sobre o qual o processo ocorre. A realização do processo é situada no tempo e no espaço, e os fazeres são mais abstratos. A oração a seguir é um exemplo desse tipo de arranjo:

[10] O Poder Judiciário recupera suas prerrogativas. (E-B-94Jn-006)

Padrão 3 - As codificações traduzem um acontecimento, e não uma ação, ou seja, elas expressam algo que se passa com o próprio Ator, e não o que ele faz. Os processos são intransitivos, visto que os resultados não se estendem a uma Meta, e respondem à pergunta o que aconteceu $a$ $x$ ? Os termos que exercem a função de Ator resguardam características da função Meta, por isso, os sentidos veiculados são mais metafóricos. 
Os eventos são abstratos e, majoritariamente, situados no tempo e no espaço.

A seguinte oração exemplifica esse padrão:

[11] Passagem de ônibus sobe 50\% no Rio. (E-B-94-Jn-017)

Padrão 4-As codificações diferenciam-se do padrão 3 somente quanto à natureza do processo: diferentemente do padrão descrito anteriormente, esse arranjo reúne mudanças mais concretas, conforme podemos ver na oração seguinte, construída com o verbo entrar.

[12] As balas o atingiram no braço, na mão esquerda e uma entrou pelo abdômen saindo pelo reto. (E-B-94-Jn-012)

Padrão 5 - Apesar de o Ator ser codificado por uma entidade humana e individualizada, ele não é o instigador da mudança, mas o participante afetado por ela. A estrutura traduz, portanto, um acontecimento, e não uma ação, ou seja, ela expressa algo que o Ator vivencia, e não o que ele faz (processo material do 'acontecer'). O evento relatado é mais concreto e situado no espaço.

Apenas uma oração do corpus se configurou dessa forma, portanto, esse não foi um padrão muito expressivo no contexto analisado. A estrutura em questão foi construída com o verbo cair:

[13] O Papa [João Paulo II], com o rosto transtornado pela dor, apertou o abdômen e, em seguida, caiu em cima de seu secretário particular. (E-B-94-Jn-012)

Padrão 6 - O fazedor da ação é representado por um agente híbrido, ou seja, a ação é atribuída a uma instituição empresarial, política ou social. A agentividade e a mudança se estendem a uma espécie inteira, portanto, a generalidade é o objetivo pragmático-discursivo mais expressivo. $\mathrm{O}$ fazer é abstrato e o evento é situado no tempo.

Como ocorreu com o padrão 5, apenas uma oração do corpus obteve esse tipo de configuração. Tal oração, transcrita a seguir, foi construída com o verbo sair. 
[14] À meia-noite de hoje o Brasil sai do mais longo período ditatorial de sua História. (E-B-94-Jn-006)

Padrão 7 - O Ator é representado por uma entidade menos humana e menos agentiva. A ação é codificada com um Escopo do tipo Processo, o que atribui à configuração um novo formato: o termo congruentemente Meta é configurado como uma expressão de natureza mais circunstancial (grupo preposicionado). A estrutura que representa essa configuração foi construída com o verbo fazer:

[15] Reforma de Collor faz terremoto na economia. (E-B-94Jn-022)

\section{PROCESSOS TRANSITIVOS}

Padrão 8 - Como no padrão 1 , as estruturas pertencentes a esse padrão tendem a codificar um Ator mais agentivo, mais humano e mais individualizado. Todavia, diferentemente do primeiro agrupamento, as mudanças efetuadas nesse padrão se estendem ao participante Meta, que é efetivamente afetado pelo desenrolar da ação. Os fazeres subdividemse em concretos e abstratos e possuem elementos de expansão do significado, tais como correferentes, grupos adverbiais de lugar, de tempo, de modo etc.

A oração costruída com o verbo reunir exemplifica esse padrão de transitividade:

[16] O presidente Ernesto Geisel reúne hoje, às $8 \mathrm{~h}$, o Conselho de Segurança Nacional para examinar a situação política do país e, 12 horas depois (20h), anunciará à Nação o recesso do Congresso, por uma cadeia de rádio e televisão. (E-B-94-Jn-003)

Padrão 9 - Esse tipo de codificação se diferencia do anterior somente pelos critérios Natureza dos processos materiais (NAP) e Expansão dos processos materiais (EXP): os fazeres são mais concretos e não há expansão do tipo realce, mas somente do tipo extensão, ou seja, na maioria das orações, há um terceiro participante - o Beneficiário. 
Como exemplo desse padrão, citamos a seguinte oração, com o verbo enviar:

[17] O primeiro-secretário do PC polonês enviou [ao Vaticano] telegrama desejando "rápida recuperação do Papa." (E-B-94Jn-012)

Padrão 10 - O participante Ator é representado por uma entidade mais agentiva e mais humana (individualizada ou genérica). Os fazeres estendem-se a um participante do tipo Meta e são codificados na forma mais congruente do significado. Diferentemente do padrão anterior, as mudanças efetuadas nesse padrão são mais abstratas - retratam, portanto, mais as alterações nas relações sociais e políticas que as mudanças no mundo físico/perceptível. O enfoque do evento incide sobre a mudança efetuada pelo Ator ao participante Meta, por isso, não existem elementos que expandam o significado, tais como localização temporal, localização espacial, participantes adicionais etc.

Como exemplo desse arranjo de transitividade, citamos o seguinte caso:

[18] Sarney lança plano da Inflação Zero. (E-B-94-Jn-016)

Padrão 11 - Os processos são do tipo mais transitivo, por isso, respondem à pergunta $o$ que $x f e z$ a $y$ ? O fazedor da ação é representado por um agente híbrido, ou seja, a ação é atribuída a uma instituição empresarial, política ou social. As mudanças efetuadas são, majoritariamente, mais abstratas. Quanto à expansão do significado, as orações apresentam elementos de expansão do tipo realce, como indicação de modo, localização de tempo e de lugar etc.

Exemplificamos o padrão 11 com a seguinte oração, construída com o verbo arquivar:

[19] STM (Superior Tribunal Militar) arquiva Riocentro em definito por 10 a 4 . (E-B-94-Jn-013) 
Padrão 12 - Esse padrão se diferencia do anterior somente pelos critérios Natureza dos processos materiais (NAP) e Expansão dos processos materiais (EXP): os fazeres são mais concretos e não há elementos que expandam, nela própria, o significado da oração. Como exemplo, citamos a oração construída com o verbo bombardear:

[20] A aviação apoiou o avanço dos tanques em Khaldes e ainda bombardeou a cidade desportiva, onde há redutos da guerrilha palestina. (E-B-94-Jn-014)

Padrão 13 - Os eventos apresentam, simultaneamente, um fazer e um acontecer. Há, portanto, um participante codificado como Ator e um participante codificado como Meta. O Ator, no entanto, foge ao padrão prototípico agentivo e resguarda algumas propriedades de um elemento causal, atribuindo à expressão do significado um aspecto mais metafórico. Os fazeres são tanto concretos como abstratos. Os elementos de expansão são do tipo realce (localização temporal, espacial etc.) e/ou elaboração (produto resultativo etc.).

A oração com o verbo envolver, exibida adiante, exemplifica o padrão 13 de transitividade:

[21] O ataque, que se seguiu a uma quebra mútua de cessar-fogo iniciado às $21 \mathrm{~h}$ (locais) de sábado, envolveu o desembarque de tropas próximos à aldeia de Baabda, a $8 \mathrm{~km}$ do centro de Beirute. (E-B-94-Jn-014)

Padrão 14 - Nesse agrupamento, o padrão de transitividade não ficou tão bem definido como nos demais. Em termos de similaridade, esse grupo reúne eventos que apresentam tanto um fazer como um acontecer (ação-processo) - os processos estendem-se, portanto, a um participante do tipo Meta. Os fazeres codificados são mais abstratos, portanto, menos perceptíveis no mundo físico, e não possuem elementos de expansão do tipo realce na mesma oração (ou seja, não apresentam grupos adverbiais de tempo, de lugar ou de modo, por exemplo). Já em termos de dissimilaridades, destacamos que esse grupo reúne processos cujo participante Ator tanto representa uma entidade híbrida como uma causalidade; as expressões do significado são tanto metonímicas como 
metafóricas, e algumas orações apresentam um terceiro participante, o Beneficiário.

Como exemplos desse agrupamento, citamos as orações construídas com os verbos dar e entregar:

[22] Mudança dá novo perfil ao governo. (E-B-94-Jn-022)

[23] Logo esquecida, a idéia renasce em janeiro de 1970, quando a Federação das Indústrias do Estado da Guanabara (FIEGA) entrega ao Governo federal um estudo e anteprojeto de lei complementar, sugerindo a medida como um remédio para a estagnação industrial do Estado-município. (E-B-94-Jn-001).

Padrão 15 - Nesse caso, as orações não veiculam uma ação, mas sim um acontecimento. O participante Ator, representado por um SN mais genérico, não é uma entidade instigadora, mas afetada, o que distancia esse tipo de configuração do protótipo de categorização dos fazeres materiais transitivos. A expressão do significado é do tipo mais congruente, e o evento é de natureza mais abstrata.

Pouco recorrente no contexto analisado, um exemplo desse padrão pode ser visto na seguinte estrutura:

[24] Um milhão de brasileiros perderam o emprego entre janeiro e maio deste ano, de acordo com a pesquisa mensal do IBGE sobre o nível de ocupação da mão-de-obra no país. (E-B-94-Jn-018)

Conforme se percebe, cada um dos quinze padrões de transitividade evoca um propósito comunicativo bastante peculiar nas notícias jornalísticas. Os padrões 1 e 8, por exemplo, veiculam elementos mais detalhados acerca dos acontecimentos narrados. Os participantes envolvidos na cena discursiva são plenamente identificados, por meio de SNs com nome próprio, bem como as circunstâncias que envolvem os fatos. O objetivo principal desse tipo de estrutura é fornecer ao leitor informações mais precisas acerca de quem fez o quê, (a quem), quando, onde e como.

Os padrões 11 e 12, por sua vez, cumprem a função de codificar ações veiculadas às esferas sociais e públicas. Por meio da metonímia, 
os fazeres são atribuídos, por exemplo, a instituições financeiras, jurídicas, sociais e políticas, em detrimento de seus representantes legais ou responsáveis. Nesses contextos discursivos, as instituições ocupam papel mais relevante que seus dirigentes específicos. Pelo fato de essas entidades organizacionais exercerem funções bastante específicas no que tange ao bom funcionamento da sociedade, as mudanças efetuadas sobre o participante do tipo Meta se encontram, na maioria das vezes, no domínio de competência dessas instituições. Assim, à Prefeitura, por exemplo, cabe a manutenção das obras arquitetônicas existentes na cidade; ao Banco Central, cabe a busca por estabilidade na economia; ao Poder Executivo, compete a elaboração de projetos, com vista à implementação de novas leis, e assim por diante. Os exemplos citados ao longo do trabalho mostram que as ações atribuídas aos agentes metonímicos se encaixam nesses enquadres sociais.

Já os padrões 3 e 4 veiculam a noção de mudança autocausada, ou seja, apesar de o processo ser provocado por um agente externo a ele, essa entidade agentiva não é identificada - seja no domínio da oração ou, de forma mais ampla, no domínio do texto. Nas notícias jornalísticas, esses padrões exercem as importantes funções de (i) enfatizar o elemento da narrativa considerado como o mais importante e (ii) ocultar o real responsável pelas mudanças efetuadas, sem, no entanto, gerar uma proposição incompleta ou chamar a atenção para a falta dessa informação.

O padrão 13, conforme foi mencionado anteriormente, cumpre as funções de enfatizar um elemento tido como o mais importante do relato e de ocultar o real responsável pelo fazer. Todavia, diferentemente dos padrões 3 e 4, esse padrão não codifica um acontecimento, mas uma ação efetuada por uma entidade não agentiva. Nesses casos, uma entidade menos volitiva e menos controladora é codificada como o Ator do processo material e a ela são atribuídos fazeres característicos de entidades humanas e instigadoras, como criar, desautorizar, fundir etc. O sistema de transitividade é organizado de modo que a causa ou o instrumento de mudança, elevados à posição de Tema, são interpretados como a informação mais relevante da narrativa. 


\section{Considerações finais}

Neste estudo, o termo transitividade foi considerado em uma acepção diferente daquela encontrada nos manuais tadicionais de gramática, que se limitam à classificação dos verbos em transitivos ou intransitivos. A noção de transitividade adotada aqui diz respeito ao modo como os significados são construídos e, por isso, considerou, concomitantemente, as dimensões léxico-gramaticais e pragmáticodiscursivas desse sistema linguístico.

A partir da ideia de que as escolhas feitas pelo usuário da língua não são aleatórias, mas são efetuadas com base nos objetivos comunicativos a que se pretende chegar, buscou-se compreender como a seleção dos elementos que operam o complexo transitivo - os processos, os participantes e as circunstâncias - se correlaciona aos propósitos comunicativos dos gêneros discursivos. Com vistas a alcançar tal objetivo, a transitividade foi analisada na totalidade da oração, e não apenas em relação ao verbo e seu complemento.

Dado nosso interesse em conhecer, de forma mais sistemática, os padrões de transitividade dos processos materiais em contextos discursivos específicos, os resultados encontrados mostraram que os oito parâmetros selecionados para descrição dos dados (caracterização dos fazeres transitivos e intransitivos, número de participantes na oração, natureza dos processos materiais, tipos de "fazeres" materiais, propriedades semânticas do Ator, formas de expressão do significado, objetivos pragmático-discursivos e expansão dos processos materiais) cumpriram a função de distinguir as diversas configurações dos processos analisados. Além disso, os resultados reiteraram a importância da Rede SOM como ferramenta para organização das informações e para o reconhecimento dos modelos linguísticos.

Os quinze padrões de transitividade encontrados nas notícias jornalísticas, além de revelarem as configurações mais significativas, permitiram averiguar como os significados são construídos nesse contexto particular de interação. Além das configurações mais congruentes (ou menos marcadas), como as representadas pelos padrões 1, 8 e 9, as necessidades de elaborar uma proposição completa (ou seja, que contenha sujeito, predicado e circunstância) e de ordenar a estrutura a partir da notação mais importante motivam a elaboração de outros arranjos, cujas configurações são menos congruentes, como as representadas pelos padrões 3, 4, 13 e 14 . 
Ainda no que tange aos padrões encontrados, as análises permitiram identificar as configurações menos recorrentes e, portanto, menos produtivas nas notícias jornalísticas. Eventos processuais mais prototípicos, como os representados pelos padrões 5 e 15 , não obtiveram muitas ocorrências. Esse tipo de estrutura confere aos relatos um tom menos dinâmico e, por isso, parecem se distanciar dos propósitos principais das notícias jornalísticas, que são informar quem fez o quê, a quem, como e quando.

Por fim, consideramos que este trabalho contribui para uma ampliação no estudo da transitividade. A descrição desse sistema a partir de critérios léxico-gramaticais e pragmático-discursivos evidencia a relevância da transitividade em termos de construção de significados. Apontamos, no entanto, a necessidade de novas investidas, como a diversificação do gênero discursivo, a ampliação do número de dados, dos tipos de processo e, quando necessário, dos parâmetros e das classes elencados. Entendemos que essas medidas poderão proporcionar melhor distribuição dos dados na Rede SOM e, consequentemente, modelos linguísticos ainda mais bem definidos.

\section{Referências}

BROCK, G. et al. clValid: an R package for cluster validation. Journal of Statistical Software, Innsbruck, Austria, v. 25, n. 4, p. 1-22, 2008.

CHAFE, W. Significado e estrutura linguística. Trad. Maria Helena de Moura Neves et al. Rio de Janeiro: Livros Técnicos e Científicos, 1979.

DAMASCENO, G. L. N. A transitividade de processos materiais em notícias jornalísticas. 2016. 248 f. Tese (Doutorado em Letras Vernáculas) - Faculdade de Letras, Universidade Federal do Rio de Janeiro, Rio de Janeiro, 2016.

DAMASCENO, G. L. N. et al. A metáfora da transitividade no gênero notícia jornalística: uma abordagem sistêmico-funcional. Signótica, Goiânia, v. 26, n. 2, p. 495-517, 2014. https://doi.org/10.5216/sig. v26i2.29444

FILLMORE, C. J. The case for case. In: BACH, E.; HARMS, R. (Org.). Universals in linguistic theory. New York: Holt; Rinnehart and Winston, 1968. p. 1-88. 
HALLIDAY, M. A. K. An introduction to functional grammar. 2. ed. London: Edward Arnold, 1994.

HALLIDAY, M. A. K.; MATTHIESSEN, C. M. I. M. An introduction to functional grammar. 3. ed. London: Arnold, 2004.

HAYKIN, S. Redes neurais: princípios e prática. 2. ed. Bookman Companhia, 2001.

HOPPER, P.; THOMPSON, S. Transitivity in grammar and discourse. Language, Washington, v. 56, n. 2, p. 251-299, 1980. https://doi. org/10.1353/lan.1980.0017

KOHONEN, T. Self-organized formation of topologically correct feature maps. Biological Cybernetics, Springer International Publishing, n. 43, p. 59-69, 1982.

KOHONEN, T. The self-organizing map. Proceedings of the IEEE, IEEE Xplore ${ }^{\circledR}$ Digital Library, v. 78, n. 9, p. 1464-1480, 1990. https://doi. org/10.1109/5.58325

KOHONEN, T. Self-organizing maps. 3. ed. Berlin-Heidelberg, Germany: Springer, 2001. https://doi.org/10.1007/978-3-642-56927-2

KOHONEN, T. Essentials of the self-organizing map. Neural Networks, n. 37, p. 52-65, 2013. https://doi.org/10.1016/j.neunet.2012.09.018

LAGE, N. Estrutura da notícia. 5. ed. São Paulo: Ática, 2003.

LAKOFF, G.; JOHNSON, M. Metáforas de la vida cotidiana. Trad. Carmen González Marín. 7. ed. Madri: Catedra, 2007.

MÜLLER, A. L. A expressão da genericidade nas línguas naturais. In: MÜLlER, A. L.; NEGRÃO, E. V.; FOLTRAN, M. J. (Org.). Semântica formal. São Paulo: Contexto, 2003. p. 153-172.

R DEVELOPMENT CORE TEAM. R: A language and environment for statistical computing. $R$ Foundation for Statistical Computing, Vienna, Austria, 2011. Disponível em: <http://www.r-project.org/> . Acesso em: nov. 2015.

WEHRENS, R.; BUYDENS, L. M. C. Self- and Super-organizing Maps in R: The Kohonen Package. Journal of Statistical Software, Innsbruck, Austria, v. 21, n. 5, p. 1-19, 2007. 
